\title{
Development of a Benchtop Method to Polymerize Lactose to Soluble Fiber
}

\section{Alexandra Kuechel and Tonya C. Schoenfuss*}

\section{Introduction}

Extrusion has been utilized for the polymerization of sugars into larger oligosaccharides. ${ }^{1,2}$ The high temperature, pressure and shear from the extruder allows for continuous chemical synthesis of oligosaccharides. ${ }^{2}$ A mixture of lactose, glucose and citric acid has been polymerized using a twin-screw extruder to yield polylactose. ${ }^{3}$ However, previous research in our lab demonstrated that the lactose in permeate and acid whey could not be polymerized using our standard extrusion method. Inhibition factors for this polymerization reaction are not currently well understood. The impact of the citric acid content and extruder feed rate have been researched ${ }^{3}$, yet chemical properties such as moisture and mineral content have not.

\section{Objective}

The objective of this study was to develop a benchtop method for polymerization to identify reaction inhibition factors before extrusion scale up.

\section{Materials and Methods}

Sample Preparation: 7 grams of a blend containing citric acid (6\%), lactose (74\%) and glucose (20\%) were added to 8 Teflon MarsXpress vessels. The vessels were closed and the product equilibrated for 48 hours when water was added.

Heating in the Microwave Reactor: The vessels were heated simultaneously in a CEM Mars 6 microwave reaction system. All vessels were continuously monitored for temperature via an internal infrared thermometer.

Polymerization Confirmation: HPLC-ELSD was used for polymerization confirmation. Cooled samples were prepared for analysis by dissolving product in water to a concentration of 50 $\mathrm{mg} / \mathrm{ml}$ and then passing the solution through ion-exchange resins made of Amberlite and Ambersep.
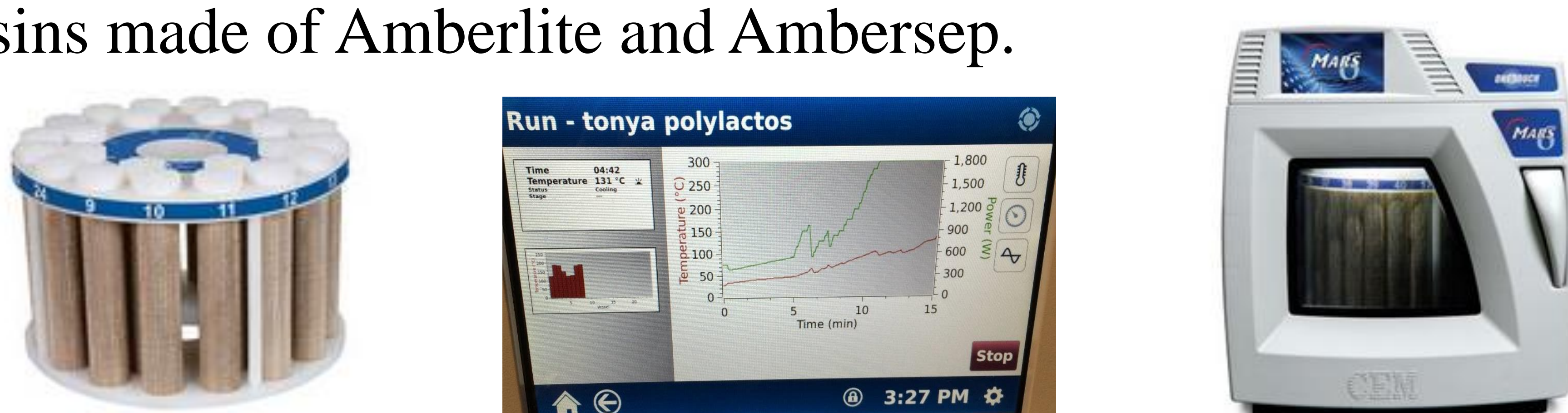

\section{Heating Profile Development}
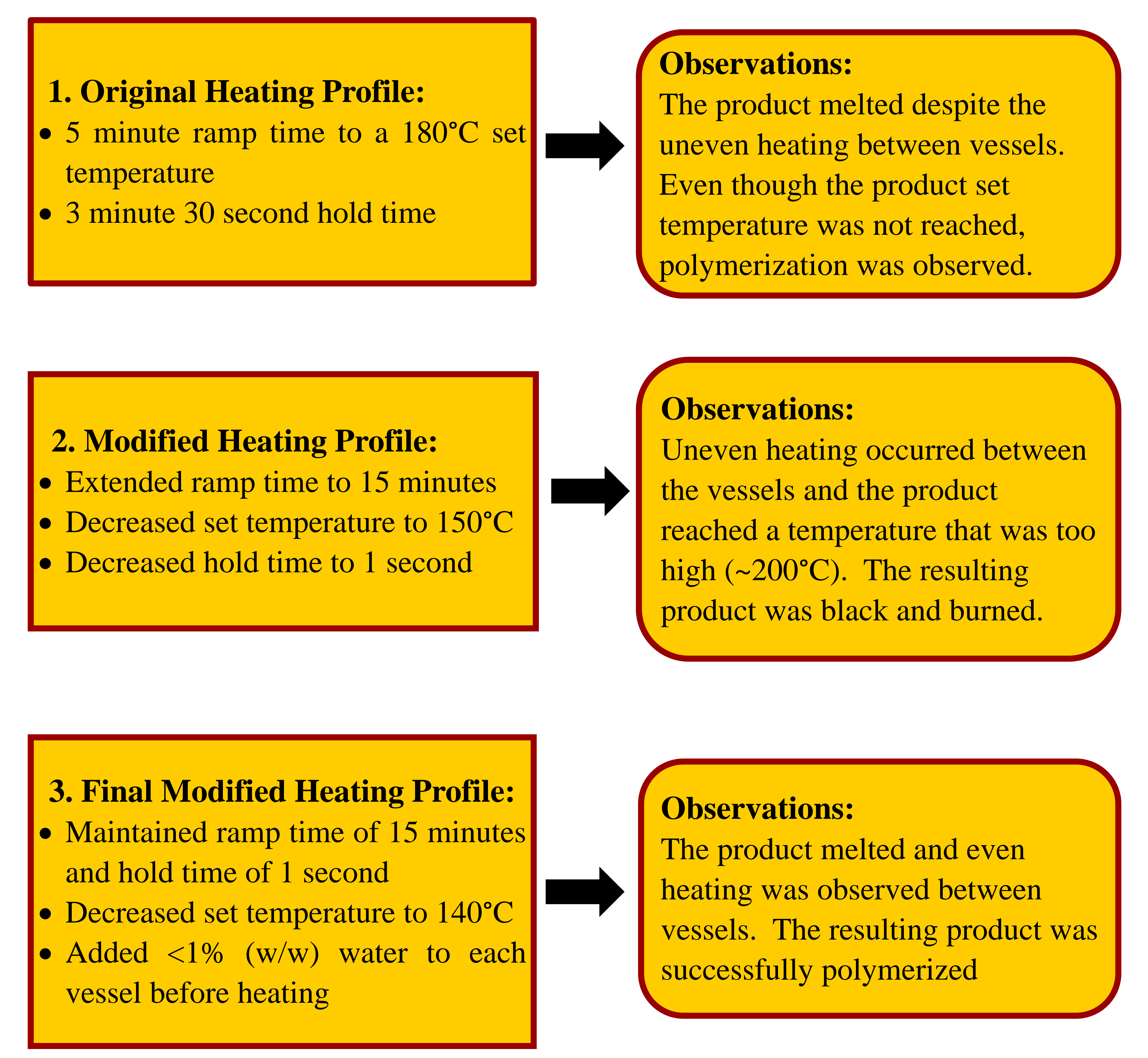

Polymerization Confirmation from Final Heating Profile

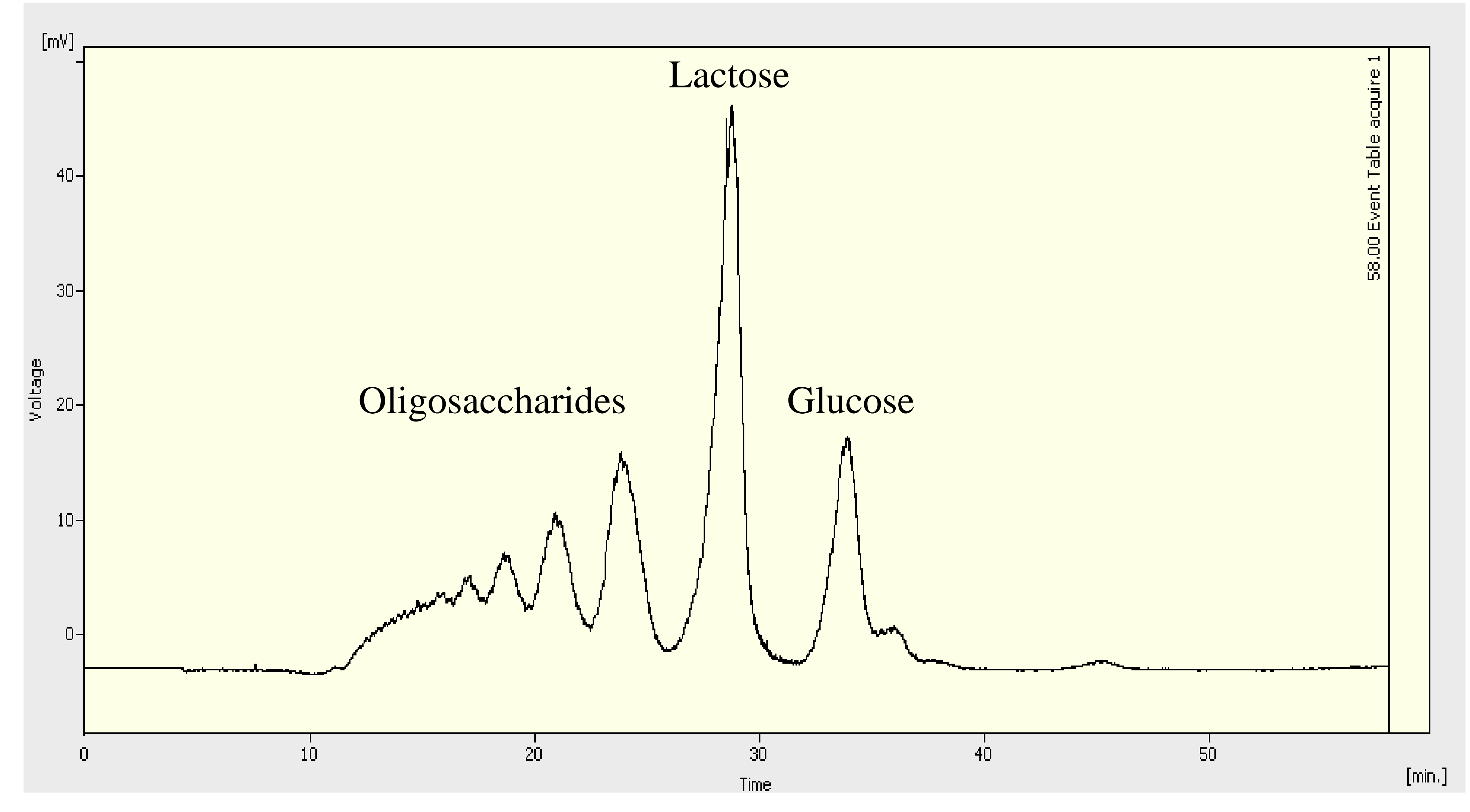

Discussion

Melting and polymerization of the lactose was possible at a lower temperature than the extrusion method.

- The Mars 6 system was under higher pressure than the open extruder system.

An increase in ramp time prevented large power surges at the end of the heating cycle that helped reach the product set temperature.

The addition of a small amount of water was necessary to consistently achieve the target temperature in all vessels for every run.

$\circ$ Addition of a polar solvent increased dipole rotation due to the microwave energy, creating more even heating.

$\circ$ Excess water could cause hydrolysis instead of polymerization.

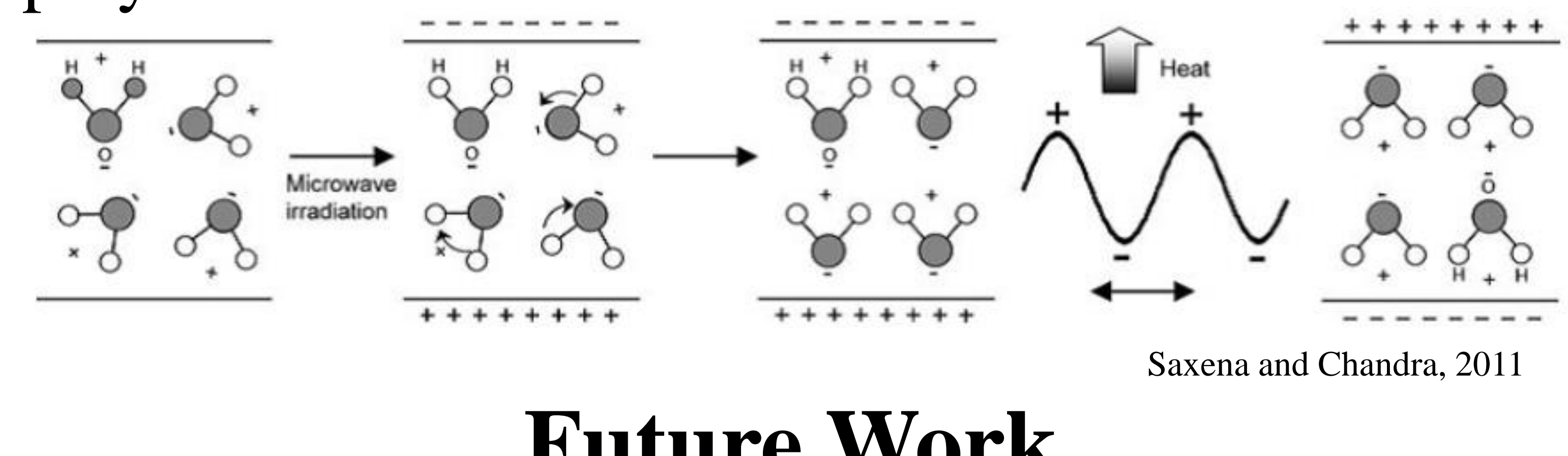

Future Work

- Optimize water addition for the final heating profile.

- Investigate the impact of moisture and mineral content on lactose polymerization to mimic acid whey composition.

- Scale up the learnings via extrusion in the pilot plant.

\section{Acknowledgements}

The researchers would like to thank the Midwest Dairy Foods Research Center for their support of this project.

\section{References}

. Hwang, J. K., Kim, C. J., \& Kim, C. T. (1997). Polymerization of sugars by extrusion. Journal of Food Science and Nutrition, 2, 296-300. 2. Hwang, J. K., Kim, C. J., \& Kim, C. T. (1998). Production of Glucooligosaccharides and Polydextrose by Extrusion Reactor. Starch Stärke, 50(2-3), 104-107.

3. Tremaine, A.J., Reid, E.M, Tyl, C.E., Schoenfuss, T.C. (2014) Polymerization of lactose by twin-screw extrusion to produce indigestible ologosaccharides. International Dairy Journal, 36, 74-81.

4. Saxena, V.K., Chandra, U. (2011) Microwave synthesis: a physical concept. Intech open access publisher

UNIVERSITY OF MINNESOTA 1334 Eckles Ave., St. Paul, MN 55108
Driven to Discover ${ }^{s M}$ 